\title{
Performance of ultralow-dose $\mathrm{CT}$ with iterative reconstruction in lung cancer screening: limiting radiation exposure to the equivalent of conventional chest $\mathrm{X}$-ray imaging
}

\author{
Huber Adrian ${ }^{1,2}$ - Landau Julia ${ }^{1}$ - Ebner Lukas ${ }^{1,3}$ • Bütikofer Yanik ${ }^{1}$ - Leidolt Lars ${ }^{1}$. \\ Brela Barbara $^{1}$ - May Michelle ${ }^{1} \cdot$ Heverhagen Johannes ${ }^{1} \cdot$ Christe Andreas $^{1}$
}

Received: 13 January 2015 /Revised: 21 December 2015 / Accepted: 23 December 2015 /Published online: 26 January 2016

(C) European Society of Radiology 2016

\begin{abstract}
Objective To investigate the detection rate of pulmonary nodules in ultralow-dose CT acquisitions.

Materials and methods In this lung phantom study, 232 nodules (115 solid, 117 ground-glass) of different sizes were randomly distributed in a lung phantom in 60 different arrangements. Every arrangement was acquired once with standard radiation dose $(100 \mathrm{kVp}, 100$ references $\mathrm{mAs})$ and once with ultralow radiation dose $(80 \mathrm{kVp}, 6 \mathrm{mAs})$. Iterative reconstruction was used with optimized kernels: I30 for ultralow-dose, I70 for standard dose and I50 for CAD. Six radiologists examined the axial 1-mm stack for solid and ground-glass nodules. During a second and third step, three radiologists used maximum intensity projection (MIPs), finally checking with computer-assisted detection (CAD), while the others first used CAD, finally checking with the MIPs.

Results The detection rate was $95.5 \%$ with standard dose (DLP $126 \mathrm{mGy}^{*} \mathrm{~cm}$ ) and $93.3 \%$ with ultralow-dose (DLP: $\left.9 \mathrm{mGy}^{*} \mathrm{~cm}\right)$. The additional use of either MIP reconstructions or CAD software could compensate for this difference. A combination of both MIP reconstructions and CAD software resulted in a maximum detection rate of $97.5 \%$ with ultralow-dose.
\end{abstract}

Huber Adrian

adrian.huber@insel.ch

1 Department of Diagnostic, Interventional and Paediatric Radiology, University Hospital Inselspital Bern, CH-3010 Bern, Switzerland

2 Department of Polyvalent and Oncological Radiology, University Hospital Pitié-Salpêtrière, Paris, France

3 Department of Radiology, Duke University Medical Center, Durham, NC, USA
Conclusion Lung cancer screening with ultralow-dose CT using the same radiation dose as a conventional chest X-ray is feasible.

Key points

- $93.3 \%$ of all lung nodules were detected with ultralowdose $C T$.

- A sensitivity of $97.5 \%$ is possible with additional image postprocessing.

- The radiation dose is comparable to a standard radiography in two planes.

- Lung cancer screening with ultralow-dose CT is feasible.

Keywords Computed tomography $\cdot$ Pulmonary nodule detection $\cdot$ Lung adenocarcinoma $\cdot$ Ultralow-dose acquisition · Diagnostic performance with low radiation dosage
Abbreviations and acronyms
CAD Computer-aided detection
MIP Maximum intensity projection

\section{Introduction}

Lung cancer accounts for $18 \%$ of cancer deaths worldwide. It is the leading cause of cancer deaths in men, and the second leading cause of cancer deaths in women after breast cancer [1]. In 1996, Kaneko et al. [2] showed that conventional chest radiography was inferior to computed tomography (CT) for lung cancer screening. Annual CT screening of patients at risk allows for the detection of early-stage lung cancer, which is curable [3]. The National Lung Cancer Screening Trial (NLST) is the first, and so far only, large multicentre study 
that showed a reduction of $20 \%$ in the mortality rate of a highrisk population following annual lung cancer screening, including 53,454 patients [4]. Other large multicentre studies such as the European randomised lung cancer CT screening trial (EUCT) or the Dutch-Belgian randomised lung cancer multi-slice CT screening trial (NELSON) are currently ongoing $[5,6]$. Now many associations recommend lung cancer screening [7-10].

Nonetheless, since there are some important arguments against lung cancer screening, it is not yet widely applied. The major concerns with lung cancer screening by $\mathrm{CT}$ are the costs generated by the repetitive CT acquisitions [11], the high detection rate of false-positive benign nodules [12] and the radiation dose [13]. Smokers and former smokers who receive an annual low-dose CT from the age of 50-75 years, with a presumed effective dose of $5.2 \mathrm{mGy}$ per CT acquisition, have a calculated additional risk of $1.8 \%(95 \%$ CI $0.5-5.5)$ for lung cancer, due to repetitive CT acquisitions [13].

The newest generation of CTs, in combination with iterative reconstruction techniques [14], allow for ultralow-dose CT acquisitions with effective doses similar to the dose of the topogram, and thus not more than the dose with conventional thoracic radiography in two projections, which is 0.05 $0.24 \mathrm{mSv}$ [15]. These ultralow-dose CT acquisitions allow a high sensitivity and diagnostic confidence for the detection of pulmonary nodules [16].

Various secondary read-out tools exist that can increase the detection rate for small lung nodules, such as the use of maximum intensity projections (MIPs) [17] or computer-aided detection (CAD) software $[18,19]$.

The aim of this lung phantom study was to investigate the sensitivity to lung nodules of an ultralow-dose CT with the same effective dose as the dose from conventional radiography, compared to a standard CT alone, as well as in combination with MIP reconstructions and CAD software.

\section{Materials and methods}

\section{Lung phantom preparation and computed tomography (CT) acquisition}

In this lung phantom study, an anthropomorphic chest phantom (Chest Phantom N1 by Kyoto Kagaku@, $43 \times 40 \times 48 \mathrm{~cm}$ ) was used. Thus, approval from the local ethics committee was not necessary. The phantom was equipped with solid $(100 \mathrm{HU} /$ $5,8,10$ and $12 \mathrm{~mm})$ and ground-glass $(-630 \mathrm{HU} / 5,8,10$ and $12 \mathrm{~mm}$ ) spherical nodules (size 5, 8,10 and $12 \mathrm{~mm}$ ) that were randomly distributed by number, location, type and size to the different lung segments, with a minimum of zero nodules and a maximum of eight nodules per phantom. In a total of 60 different phantom arrangements, 232 nodules have been placed, randomly assigned to a lung side, lung segment and peripheral or central location (the inner half of the lung toward the hilum versus the outer half of the lung toward the ribs, radially): 115 were solid and 117 had a ground-glass density (Fig. 1). Five phantoms did not contain any nodules. The phantoms were acquired twice: once with a standard radiation dose, and once with an ultralow radiation dose.

All acquisitions were performed on a Somatom Definition Flash CT (Siemens Forchheim, Germany) featuring iterative reconstruction algorithms (IRIS, Siemens, Germany) and a detector system with integrated readout electronics (Stellar detector, Siemens Forchheim, Germany) with a gantry rotation time of $0.28 \mathrm{~s}$. The pitch was 2.2 and the collimation was $0.6 \mathrm{~mm}$. The standard acquisition was performed with $100 \mathrm{kVp}$ in the care-mAs mode with a reference tube-current time product of $100 \mathrm{mAs}$. The care-kV mode was disabled. For the ultralowdose acquisition with a tube potential of $80 \mathrm{kVp}$ and a tube current-time product of $6 \mathrm{mAs}$, care- $\mathrm{kV}$ and reference $\mathrm{mAs}$ were disabled. These acquisition settings resulted in a volume CT dose index (CTDIvol) of $3.15 \mathrm{mGy}$ for the standard acquisitions and a CTDIvol of $0.22 \mathrm{mGy}$ for the ultralow-dose acquisitions. The corresponding Dose-length product for a scan length of $40 \mathrm{~cm}$ was $126 \mathrm{mGy} * \mathrm{~cm}$ and $9 \mathrm{mGy} * \mathrm{~cm}$ (Table 1).

The images for both acquisitions were reconstructed in axial stacks with a slice thickness of $1 \mathrm{~mm}$ and an increment of $1 \mathrm{~mm}$ in a lung parenchyma window (level: -600 ; window width: 1,200), using the vendor specific iterative reconstruction algorithm (iterative reconstruction in imaging space [IRIS]; Siemens, Erlangen, Germany) with the level 3 reconstruction process, integrated in syngo.via (Siemens Healthcare). Based on data from previous pilot studies, investigating the optimum convolution kernel in ultralow-dose acquisitions [20], radiologists achieved a significantly higher detection rate looking at the 1-mm axial image stack reconstructed with a $\mathrm{I} 30$ convolution kernel compared to the I70 convolution kernel normally used in standard $\mathrm{CT}$, while the CAD software performed best with a I50 convolution kernel.

To compare the highest possible detection rates, we consequently used the standard I70 convolution kernel for the standard acquisition, the I30 convolution kernel for the ultralowdose acquisition and the I50 convolution kernel for the Lung CAD VD10 Mode 2 software. The standard acquisition axial $1 \mathrm{~mm}$ stack and the ultralow-dose acquisition axial $1 \mathrm{~mm}$ stack were used with the CAD software as well as for the reconstruction with maximum intensity projections (MIP, slice thickness $8 \mathrm{~mm}$, increment $2 \mathrm{~mm}$ ).

\section{Dose calculation}

The effective dose was calculated by multiplying the DLP from the $\mathrm{CT}$ protocol with the conversion factors of ICRP 103 [21], which are $0.0147\left[\mathrm{mSv} /\left(\mathrm{mGy}^{*} \mathrm{~cm}\right)\right]$ for an adult thoracic CT acquisition with $80 \mathrm{kVp}$ and $0.0144[\mathrm{mSv} /$ $(\mathrm{mGy} * \mathrm{~cm})]$ for $100 \mathrm{kVp}$. 
Fig. 1 Image comparision (1$\mathrm{mm}$ axial stack): the standard acquisitions (tube voltage: 100 $\mathrm{kVp}$, tube current: $100 \mathrm{mAs}$, effective dose: $1.81 \mathrm{mSv}$ ) with a solid (a) and a ground-glass nodule (b) compared to the ultralowdose acquisitions (tube voltage: $80 \mathrm{kVp}$, tube current-time product: $6 \mathrm{mAs}$, effective dose: $0.135 \mathrm{mSv}$ ) of the same solid (c) and ground-glass $(\mathbf{d})$ nodule

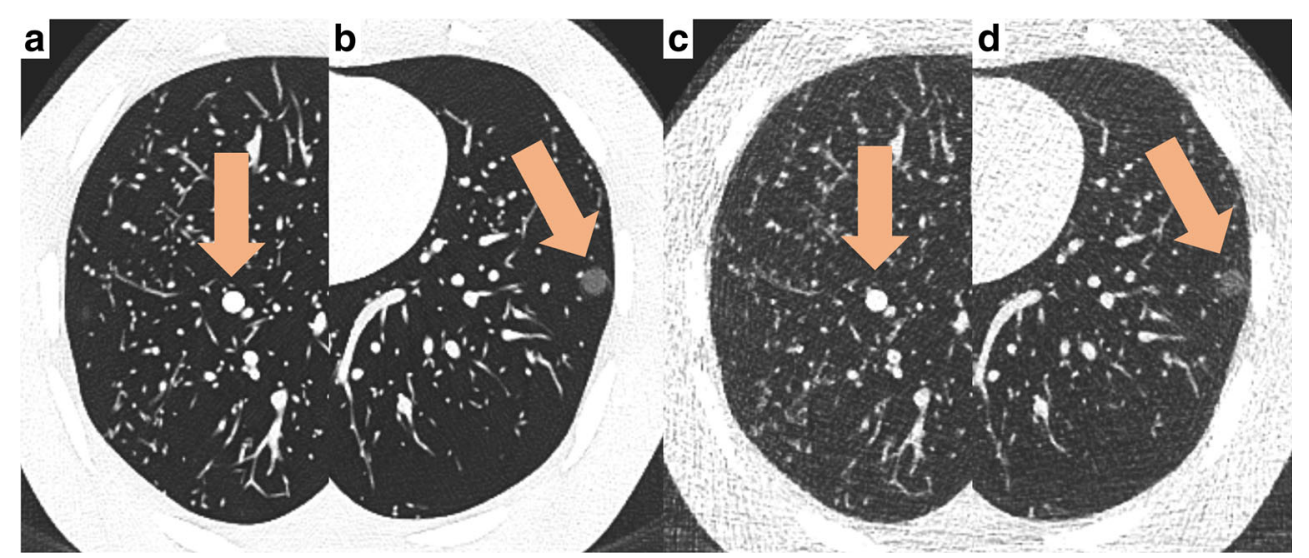

\section{Read-out}

The read-out was conducted on a Picture Archiving and Communication System (PACS R11.4.1, 2009; Philips, Best, Netherlands; Sectra, Linkoping, Sweden). A total of six radiologists with 3-7 years of experience in thoracic radiology examined the ultralow-dose and the standard acquisitions in three steps with an interval of at least 2 weeks between readout sessions. First, each reader examined the axial 1-mm image stack for solid and ground-glass nodules without any knowledge of additional MIPs or CAD. The location of the nodules (right/left lung and table position), nodule type (solid/ ground-glass) and nodule size (in millimeters) were noted. For the second and third read-outs, two groups of readers were formed (three readers each with comparable experience in thoracic imaging between the groups); the first read-out group examined the MIP reconstructions during the second read-out, finally checking with the CAD (third read-out), while the second group used CAD during the second read-out, finally referred to the MIPs (third read-out).

\section{Statistical analysis}

The comparisons of nodule detection with standard CT and ultralow-dose CT with and without MIP reconstructions and CAD software were performed with the McNemar test [22]. The differences in the radiation doses between standard and ultralow-dose CT were compared with Wilcoxon's test for paired samples that are not normally distributed [23]. The chi-square test was applied to the comparison of the central and peripheral locations of the nodules. Sensitivity, specificity, positive predictive value and negative predictive value for lung nodule detection were calculated on a per-lung segment basis for the standard-dose and the ultralow-dose acquisitions with and without the additional use of MIP/CAD.

Table 1 Acquisition protocol and reconstruction settings for the standard and the ultralow-dose acquisitions

\begin{tabular}{|c|c|c|}
\hline & Standard acquisitions & Ultralow-dose acquisitions \\
\hline Dose & $\begin{array}{l}\text { CTD1vol } 3.15 \text { mGy/DLP } 126 \mathrm{mGy} * \mathrm{~cm} \\
\text { (40 cm scan-length) }\end{array}$ & CTD1vol 0.22 mGy/DLP: 9 mGy*cm (40-cm scan length) \\
\hline Tube voltage & $100 \mathrm{kVp}$ & $80 \mathrm{kVp}$ \\
\hline Tube current-time product & 100 reference $\mathrm{mAs}$ & $6 \mathrm{mAs}$ \\
\hline Primary collimation & \multicolumn{2}{|l|}{$0.6 \mathrm{~mm}$} \\
\hline Gantry rotation time & \multicolumn{2}{|l|}{$0.28 \mathrm{~s}$} \\
\hline Pitch & \multicolumn{2}{|l|}{2.2} \\
\hline Standard readout reconstructions & \multicolumn{2}{|c|}{$\begin{array}{l}\text { Axial stacks with a slice thickness of } 1 \mathrm{~mm} \text { and an increment of } 1 \mathrm{~mm} \text { in a lung parenchyma window (level: }-600 \text {; } \\
\text { window width: } 1,200 \text { ) with an } 170 \text { convolution kernel for the standard acquisitions and an } 130 \text { convolution } \\
\text { kernel for the ultralow-dose acquisitions }\end{array}$} \\
\hline Readout with MIP reconstructions & \multicolumn{2}{|c|}{$\begin{array}{l}\text { MIP axial stacks with a slice thickness of } 8 \mathrm{~mm} \text { and an increment of } 2 \mathrm{~mm} \text { in a lung parenchyma window } \\
\text { (level: }-600 \text {; window width: } 1,200 \text { ) with an } 170 \text { convolution kernel for the standard acquisitions and an } 130 \\
\text { convolution kernel for the ultralow-dose acquisitions }\end{array}$} \\
\hline Readout with the CAD software & \multicolumn{2}{|c|}{$\begin{array}{l}\text { Axial stacks with a slice thickness of } 1 \mathrm{~mm} \text { and an increment of } 1 \mathrm{~mm} \text { in a lung parenchyma window } \\
\text { (level: }-600 \text {; window width: } 1,200) \text { with an } 150 \text { convolution kernel }\end{array}$} \\
\hline
\end{tabular}

MIP Maximum intensity projection 
To calculate the inter-reader variability, a non-weighted binary $\mathrm{K}$-statistic for multiple readers was used by computing the arithmetic mean of the $\mathrm{K}$-values of each pair of readers $(\mathrm{K}$ value $0-0.2$ poor; $0.21-0.4$ fair; $0.41-0.6$ moderate; $0.61-0.8$ substantial; 0.81-1 almost perfect), using the MedCalc ${ }^{\circledR}$ software $[24,25]$. The $\mathrm{k}$-statistic was performed with and without the additional use of MIP and CAD, once for the standard low-dose CTs and once for the ultralow-dose CTs.

The McNemar test, Wilcoxon's test, the chi-square test and the Kappa statistic analysis were performed using MedCalc ${ }^{\circledR}$ software, version 7.6.0.0. (MedCalc Software, Mariakerke, Belgium) [26].

\section{Results}

\section{Dose calculation}

The estimated effective dose was $1.81 \mathrm{mSv}$ for standard acquisition (DLP: $126\left[\mathrm{mGy}^{*} \mathrm{~cm}\right] * 0.0144[\mathrm{mSv} /(\mathrm{mGy} * \mathrm{~cm})]$ ) and $0.135 \mathrm{mSv}$ for ultralow-dose acquisition (DLP: 9 $[\mathrm{mGy} * \mathrm{~cm}] * 0.0147[\mathrm{mSv} /(\mathrm{mGy} * \mathrm{~cm})])$. The mean effective dose of ultralow-dose acquisition consisted of $0.074 \mathrm{mSv}$ from the acquisition of the topogram alone and only 0.059 from the actual Flash spiral.

\section{Per-nodule and per-segment analysis}

The overall detection rate was $95.5 \%( \pm 6.6 \%$ standard deviation) with standard CT and $93.3 \%( \pm 4.3 \%)$ with ultralowdose CT (Table 2). If the read-outs from both standard CT and ultralow-dose CT were enhanced by additional MIP reconstructions, the detection rate was $96.7 \%( \pm 3.8 \%)$ and $95.4 \%( \pm 3.4 \%)$, with no significant difference between the two groups. The group that used CAD software detected $99.7 \%( \pm 0.4 \%)$ and $97.7 \%( \pm 1.4 \%)$ of the nodules, with a minimal but significant difference (Table 2). The six readers all together detected a total of 11 false-positive nodules on the ultralow-dose acquisitions and a total of 12 false-positive nodules on the standard acquisitions, compared to a total of 1,357 and 1,377 true-positive nodules for the standard and ultralowdose acquisition with the additional use of MIP and CAD. The mean sensitivity, specificity, and positive and negative predictive values of all readers are summarized in Table 3 .

\section{Inter-reader variability}

The $\mathrm{K}$-statistic showed an almost perfect mean unweighted inter-reader variability value of $k=0.91$ for the ultralowdose $\mathrm{CT}$ and a mean $\mathrm{K}=0.96$ for the ultralow-dose $\mathrm{CT}$ with the additional use of MIP and CAD, compared to $\mathrm{K}=0.92$ and $\mathrm{K}=0.98$ with standard CT.

\section{Influence of nodule size, density and location}

While solid nodules had a significantly better detection rate with standard CT $(94.2 \% \pm 7.1 \%)$ compared to ultralow-dose CT $(91.0 \% \pm 6.0 \%$, p-value $=0.006)($ Table 4$)$, there was no significant difference between the standard CT $(96.9 \% \pm 6.3 \%)$ and the ultralow-dose CT $(95.6 \% \pm 2.9 \%$, $\mathrm{p}$-value $=0.188)$ for the detection of ground-glass nodules (Table 5).

An analysis of the detection rate per nodule diameter showed that only the smallest nodules with diameters of $5 \mathrm{~mm}$ were detected at a significantly lower rate with ultralow-dose CT (standard dose $89.9 \% \pm 18 \%$ vs. ultralow-dose $83.9 \% \pm 8.8 \%$; $p$-value $=0.0075$ ). The lower detection rate of these small nodules using ultralow-dose CT was no longer significant when MIP reconstructions were used (Fig. 2), resulting in detection rates of $89.1 \% \pm 6.3 \%$ and $93.7 \% \pm 4.5 \%$ for ultralow-dose CT when MIP reconstructions and CAD were used, respectively (Table 6). A separate analysis of the ground-glass and the solid nodules per size showed a slight sensitivity drop for the 8-and 5-mm solid nodules for both standard and ultralow-dose acquisition, while for the ground-glass nodules, a drop of sensitivity was observed just for the smallest 5 -mm ground-glass nodules. The 5-mm ground-glass nodules were detected with a similar sensitivity than the 8 -mm solid nodules (Table 7).

There was no significant difference in the detection of nodules located in peripheral areas versus central areas ( $p$ value $=0.28$ ).

\section{Combination of computer-aided detection and maximum intensity projections}

The combination of MIP and CAD resulted in nodule detection sensitivity of $98.9 \%( \pm 2.0 \%)$ for standard CT and $97.5 \%$ $( \pm 2.5 \%)$ for ultralow-dose $\mathrm{CT}(\mathrm{p}=0.033)$.

\section{Discussion}

The aim of this lung phantom study was to evaluate the lung nodule detection rate in ultralow-dose $\mathrm{CT}$ acquisitions using iterative reconstructions, and to investigate the additional use of MIP reconstructions and CAD software.

The overall detection rate of $93.3 \%$ for all pulmonary nodules with ultralow-dose acquisition was very similar to the standard acquisition with $95.5 \%$. This small difference could be offset with the use of MIP reconstructions, resulting in a detection rate of $95.4 \%$ with ultralow-dose CT, or with the use of CAD software resulting in an even higher detection rate of $97.4 \%$ for ultralow-dose CT.

The detection rates in this study were similar to a prior lung phantom study that showed a detection rate of $91 \%$ for 
Table 2 The sensitivity of standard and ultralow-dose acquisitions for all lung nodules with and without the assistance of maximum intensity projection (MIP) and computer-assisted detection (CAD)

\begin{tabular}{|c|c|c|c|c|c|c|c|c|c|c|}
\hline \multirow[t]{2}{*}{ Groups } & \multicolumn{4}{|c|}{ Standard acquisitions } & \multicolumn{6}{|c|}{ Ultralow-dose acquisitions } \\
\hline & Sensitivity \pm SD & $\begin{array}{l}\text { Sensitivity with } \\
\qquad \mathrm{MIP} \pm \mathrm{SD}\end{array}$ & $\mathrm{p}_{1}$ & $\begin{array}{l}\text { Sensitivity with } \\
\mathrm{MIP} \text { and } \\
\mathrm{CAD} \pm \mathrm{SD}\end{array}$ & Sensitivity \pm SD & $\mathrm{p}_{2}$ & $\begin{array}{l}\text { Sensitivity with } \\
\mathrm{MIP} \pm \mathrm{SD}\end{array}$ & $\mathrm{p}_{3}$ & $\mathrm{p}_{4}$ & $\begin{array}{l}\text { Sensitivity with MIP } \\
\text { and } C A D \pm S D\end{array}$ \\
\hline A & $\begin{array}{l}92.2 \% \pm 8.0 \% \\
\text { Sensitivity with }\end{array}$ & $\begin{array}{l}96.7 \% \pm 3.8 \% \\
\text { CAD }\end{array}$ & 0.001 & $98.1 \% \pm 2.6 \%$ & $\begin{array}{l}92.1 \% \pm 4.6 \% \\
\text { Sensitivity with }\end{array}$ & $\begin{array}{c}1.000 \\
\mathrm{CAD} \pm \mathrm{S}\end{array}$ & $\begin{array}{l}95.4 \% \pm 3.4 \% \\
D\end{array}$ & 0.100 & 0.025 & $97.3 \% \pm 3.3 \%$ \\
\hline B & $98.9 \% \pm 0.7 \%$ & $99.7 \% \pm 0.4 \%$ & 0.188 & $99.7 \% \pm 0.4 \%$ & $94.5 \% \pm 3.5 \%$ & $<0.001$ & $97.7 \% \pm 1.4 \%$ & 0.001 & 0.007 & $97.7 \% \pm 1.4 \%$ \\
\hline Mean & $95.5 \% \pm 6.6 \%$ & & & $98.9 \% \pm 2.0 \%$ & $93.3 \% \pm 4.3 \%$ & 0.002 & & & & $97.5 \% \pm 2.5 \%$ \\
\hline
\end{tabular}

Both groups started with the 1-mm axial stacks, once looking at the standard acquisitions, once at the ultralow-dose acquisitions. In a second step, for both acquisitions, the readers additionally looked at MIP reconstructions and used a CAD software. While group A first looked at the MIP reconstructions and then checked with the CAD software, group B first used the CAD software, finally checking with the MIP reconstructions

$S D$ standard deviation, $p i$ standard acquisitions vs. standard acquisitions with MIP and CAD, $p_{2}$ axial stack standard acquisitions vs. axial stack ultralowdose acquisitions, $p_{3}$ axial stack ultralow-dose acquisitions vs. ultralow-dose acquisitions with MIP and CAD, $p_{4}$ standard acquisitions with MIP and CAD vs. ultralow-dose with MIP and CAD

standard CT acquisition and $97 \%$ of standard acquisition with CAD [18], and also to studies investigating CT acquisitions of real patients, such as the study of Veronesi et al. [27] that showed a sensitivity of $90 \%$ with a standard lung CT protocol. A recent study by Doo et al. [28], using exactly the same anthropomorphic chest phantom as the present study, investigated the detectability of 5-mm and 8-mm ground-glass nodules ( -630 and $-800 \mathrm{HU})$ with a low-dose acquisition and iterative construction (effective dose of $0.47 \mathrm{mSv}$ ) [28]. The resulting sensitivity of $89 \%$ for $8-\mathrm{mm}$ ground-glass nodules was slightly lower than in the present study (96.2\%). However, for the 5-mm ground-glass nodules, there is a striking difference between the results of Doo et al. with a sensitivity of $49 \%$ and the present study, with a sensitivity of $86.7 \%$ (Table 7). One possible explanation for this difference is that in the present study exclusively ground-glass nodules with a density of $-630 \mathrm{HU}$ were used, while Doo et al. also used lower density $-800 \mathrm{HU}$ nodules. These smallest 5-mm, very low-density $-800 \mathrm{HU}$ ground-glass nodules seem to be very hard to detect with an important drop of sensitivity for the 5- $\mathrm{mm}$ ground-glass nodules in the study of Doo et al. However, these very low-density ground-glass nodules have not been investigated in the present study.

Detection rates of lung nodules were very high for standard-dose as well as for ultralow-dose acquisition, especially when using additional MIP reconstructions or a lung CAD software. While there was not a significantly different detection rate between ultralow-dose CT with MIPs and standard CT with MIPs, ultralow-dose CT with CAD was marginally, but significantly, inferior to standard CT with CAD. In a comparison of MIPs and CAD, MIPs showed a slightly higher added value than $\mathrm{CAD}$ in the standard dose setting, while CAD was slightly better in the ultralow-dose setting.

A combination of both MIP reconstructions and CAD software resulted in maximum detection rates of $97.5 \%$ for the ultralow-dose acquisitions and of $98.9 \%$ for the standard acquisition; thus, there was no real benefit in combining MIP reconstructions and $\mathrm{CAD}$ software.

After an analysis of the detection rates of the different sizes of the lung nodules, the only significant difference between
Table 3 The per-lung segment analysis of the mean performance of all readers with the sensitivity, the specificity, the positive predictive value and the negative predictive value of standard and ultralow-dose acquisitions including all lung nodules with and without the assistance of maximum intensity projection (MIP) and computer-assisted detection (CAD)

\begin{tabular}{llllll}
\hline & \multicolumn{2}{l}{ Standard acquisitions } & & \multicolumn{2}{l}{ Ultralow-dose acquisitions } \\
\cline { 2 - 3 } \cline { 6 - 7 } & $\begin{array}{l}\text { Readout without } \\
\text { MIP and CAD }\end{array}$ & $\begin{array}{l}\text { Readout with } \\
\text { MIP and CAD }\end{array}$ & & $\begin{array}{l}\text { Readout without } \\
\text { MIP and CAD }\end{array}$ & $\begin{array}{l}\text { Readout with } \\
\text { MIP and CAD }\end{array}$ \\
\hline Sensitivity \pm SD & $95.5 \% \pm 6.6 \%$ & $98.9 \% \pm 2.0 \%$ & & $93.3 \% \pm 4.3 \%$ & $97.5 \% \pm 2.5 \%$ \\
$\mathrm{Specificity} \pm$ SD & $99.8 \% \pm 0.3 \%$ & $99.8 \% \pm 2.7 \%$ & & $99.8 \% \pm 0.3 \%$ & $99.8 \% \pm 0.3 \%$ \\
$\mathrm{PPV} \pm \mathrm{SD}$ & $99.1 \% \pm 1.1 \%$ & $99.1 \% \pm 0.4 \%$ & & $99.2 \% \pm 1.1 \%$ & $99.2 \% \pm 1.0 \%$ \\
$\mathrm{NPV} \pm \mathrm{SD}$ & $98.8 \% \pm 0.6 \%$ & $99.7 \% \pm 0.3 \%$ & & $98.2 \% \pm 0.7 \%$ & $99.3 \% \pm 0.5 \%$ \\
\hline
\end{tabular}

The readers started with the 1-mm axial stacks, once looking at the standard acquisitions, once at the ultralowdose acquisitions. In a second step, for both acquisitions, the readers additionally looked at MIP reconstructions and used a CAD software

$S D$ standard deviation, $P P V$ positive predictive value, $N P V$ negative predictive value 
Table 4 The mean sensitivity of standard and ultralow-dose acquisitions for solid lung nodules with and without the assistance of maximum intensity projection (MIP) and computer-assisted detection (CAD)

\begin{tabular}{|c|c|c|c|c|c|c|c|c|}
\hline \multirow[t]{2}{*}{ Groups } & \multicolumn{3}{|c|}{ Standard acquisitions } & \multicolumn{5}{|c|}{ Ultralow-dose acquisitions } \\
\hline & Sensitivity $\pm \mathrm{SD}$ & $\begin{array}{l}\text { Sensitivity with } \\
\mathrm{MIP} \pm \mathrm{SD}\end{array}$ & $\begin{array}{l}\text { Sensitivity with } \\
\mathrm{MIP} \text { and } \mathrm{CAD} \pm \mathrm{SD}\end{array}$ & Sensitivity $\pm \mathrm{SD}$ & $\mathrm{p}_{1}$ & $\begin{array}{l}\text { Sensitivity with } \\
\mathrm{MIP} \pm \mathrm{SD}\end{array}$ & $\mathrm{p}_{2}$ & $\begin{array}{l}\text { Sensitivity with } \\
\text { MIP and } \mathrm{CAD} \pm \mathrm{SD}\end{array}$ \\
\hline A & $\begin{array}{l}90.1 \% \pm 8.1 \% \\
\text { Sensitivity with } C\end{array}$ & $\begin{array}{l}96.2 \% \pm 5.3 \% \\
\mathrm{AD}\end{array}$ & $98.0 \% \pm 2.9 \%$ & $\begin{array}{l}88.4 \% \pm 6.0 \% \\
\text { Sensitivity with }\end{array}$ & $\begin{array}{r}0.418 \\
\mathrm{AD} \pm \mathrm{SD}\end{array}$ & $93.0 \% \pm 5.8 \%$ & 0.110 & $96.2 \% \pm 5.3 \%$ \\
\hline $\mathrm{B}$ & $98.3 \% \pm 1.5 \%$ & $99.4 \% \pm 0.8 \%$ & $99.4 \% \pm 0.8 \%$ & $93.6 \% \pm 4.7 \%$ & 0.001 & $97.4 \% \pm 1.4 \%$ & 0.581 & $97.4 \% \pm \mathrm{L} 4 \%$ \\
\hline Mean & $94.2 \% \pm 7.1 \%$ & & $98.7 \% \pm 2.2 \%$ & $91.0 \% \pm 6.0 \%$ & 0.006 & & & $96.8 \% \pm 3.9 \%$ \\
\hline
\end{tabular}

Both groups started with the 1-mm axial stacks, once looking at the standard acquisitions, once at the ultralow-dose acquisitions. In a second step, for both acquisitions, the readers additionally looked at MIP reconstructions and used a CAD software. While group A first looked at the MIP reconstructions and then checked with the CAD software, group B first used the CAD software, finally checking with the MIP reconstructions

$S D$ standard deviation, $p_{I}$ standard acquisitions vs. ultralow-dose acquisitions, $p_{2}$ standard acquisitions vs. ultralow-dose acquisitions with MIP and CAD

the two acquisitions was measured for the smallest nodules $(5 \mathrm{~mm})$. These nodules were detected with a sensitivity of $83.9 \%$ with ultralow-dose CT, compared to a sensitivity of $89.9 \%$ with standard CT. Even in an isolated analysis of the 5$\mathrm{mm}$ nodules, the inferior sensitivity of ultralow-dose CT could be offset by using MIP reconstructions (89.1\%) or CAD software $(93.7 \%)$. Ground-glass nodules in general had a slightly better detection rate than solid nodules, with no significant difference between the standard dose and the ultralow-dose with or without MIP reconstructions/CAD. One possible explanation for this finding was the phantom anatomy itself, in which the lung parenchyma is slightly darker than the usual ground-glass appearance in real patients, depending on how well the patients are able to inspire during $\mathrm{CT}$ acquisition. On the other hand, the solid nodules have a very similar density to the underlying artificial bronchovascular bundles, and are thus probably more difficult to detect. However, studies using CT acquisitions of real patients have also shown a higher detection rate for ground-glass nodules compared to solid nodules, for both human readers and CAD software $[29,30]$.
This is an interesting point since small solid pulmonary nodules are less likely to be malignant than large solid nodules and ground-glass nodules [31], and, thus, small solid nodules show a higher false-positive rate [32]. Additionally, the incidence of lung adenocarcinoma, which often presents as peripheral ground-glass nodules in the early stages, has increased [33].

The slightly inferior detection rate of the small solid 5$\mathrm{mm}$ nodules in ultralow-dose acquisitions could, thus, be acceptable since the relatively low incidence of lung cancer compared to frequently detected lung nodules in a lung cancer screening population, as well as the falsepositive nodules, are some of the major problems of lung cancer screening.

The Fleischner Society gave recommendations for the management of detected lung nodules depending on nodule size [34], but so far they have not proposed how to follow up lung nodules detected in lung cancer screening. There is such a suggestion based on preliminary data of the NELSON CTscreening trial, recommending no follow-up for small nodules $<5 \mathrm{~mm}$, follow-up with calculation of volume doubling time

Table 5 The mean sensitivity of standard and ultralow-dose acquisitions for ground glass nodules with and without the assistance of maximum intensity projection (MIP) and computer-assisted detection (CAD)

\begin{tabular}{|c|c|c|c|c|c|c|c|c|}
\hline \multirow[t]{2}{*}{ Groups } & \multicolumn{3}{|c|}{ Standard acquisitions } & \multicolumn{5}{|c|}{ Ultralow-dose acquisitions } \\
\hline & Sensitivity \pm SD & $\begin{array}{l}\text { Sensitivity with } \\
\mathrm{MIP} \pm \mathrm{SD}\end{array}$ & $\begin{array}{l}\text { Sensitivity with MIP } \\
\text { and } \mathrm{CAD} \pm \mathrm{SD}\end{array}$ & Sensitivity \pm SD & $\mathrm{p}_{1}$ & $\begin{array}{l}\text { Sensitivity with } \\
\mathrm{MIP} \pm \mathrm{SD}\end{array}$ & $\mathrm{p}_{2}$ & $\begin{array}{c}\text { Sensitivity with MIP } \\
\text { and } C A D \pm S D\end{array}$ \\
\hline \multirow[t]{2}{*}{ A } & $94.3 \% \pm 8.1 \%$ & $97.2 \% \pm 4.0 \%$ & $98.3 \% \pm 2.4 \%$ & $95.7 \% \pm 3.2 \%$ & 0.418 & $97.7 \% \pm 1.1 \%$ & 0.017 & $98.3 \% \pm 1.2 \%$ \\
\hline & \multicolumn{3}{|c|}{ Sensitivity with $\mathrm{CAD} \pm \mathrm{SD}$} & \multicolumn{5}{|c|}{ Sensitivity with $\mathrm{CAD} \pm \mathrm{SD}$} \\
\hline $\mathrm{B}$ & $99.4 \% \pm 1.0 \%$ & $100.0 \pm 0.0 \%$ & $100.0 \% \pm 0.0 \%$ & $95.4 \% \pm 2.5 \%$ & 0.0001 & $98.0 \% \pm 1.5 \%$ & 0.125 & $98.0 \% \pm 1.5 \%$ \\
\hline Mean & $96.9 \% \pm 6.3 \%$ & & $99.1 \% \pm 1.9 \%$ & $95.6 \% \pm 2.9 \%$ & 0.188 & & & $98.1 \% \pm 1.3 \%$ \\
\hline
\end{tabular}

Both groups started with the 1-mm axial stacks, once looking at the standard acquisitions, once at the ultralow-dose acquisitions. In a second step, for both acquisitions, the readers additionally looked at MIP reconstructions and used a CAD software. While group A first looked at the MIP reconstructions and then checked with the CAD software, group B first used the CAD software, finally checking with the MIP reconstructions

$S D$ standard deviation, $p_{1}$ standard acquisitions vs. ultralow-dose acquisitions, $p_{2}$ standard acquisitions vs. ultralow-dose acquisitions with MIP and CAD 
Fig. 2 Per-nodule diameter analysis: mean sensitivity of standard and ultralow-dose CT with and without assistance of maximum intensity projection (MIP) and computer-aided detection (CAD)

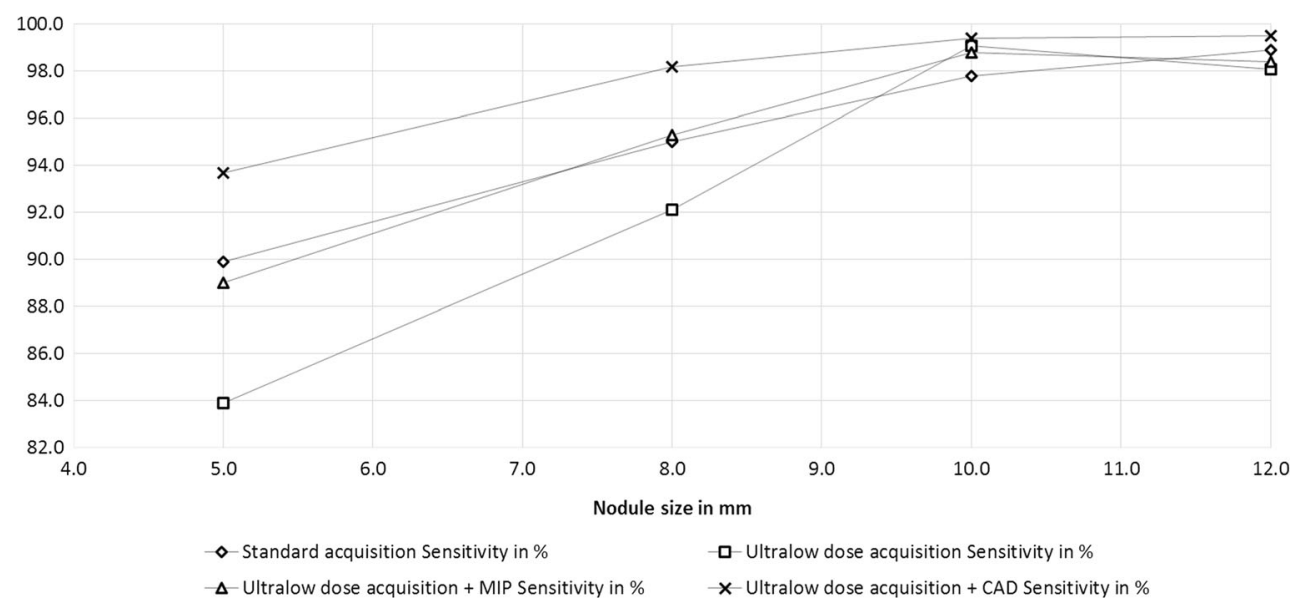

for intermediate nodules of 5-10 $\mathrm{mm}$, and immediate diagnostic evaluation of large nodules of $10 \mathrm{~mm}$ or more [35].

If the ultralow-dose CT is not performed for lung cancer screening but for surveillance of pulmonary metastasis in patients with a known malignancy, detection of very small solid nodules is crucial; thus, ultralow-dose acquisition should be performed at least with additional use of MIP reconstructions or, if available, a lung CAD software.

The NLST showed for the first time a mortality reduction of $20 \%$ with lung cancer screening in a high-risk screening population (aged 55-74 years with $\geq 30$ pack-years of smoking) [4]. Although many associations now recommend lung cancer screening, there are still on-going discussions as well as on-going, large multicentre trials such as the NELSON trial [6]. Nevertheless, Bach et al. [36] calculated that for 2, 500 screened patients in the NLST with repetitive CT acquisitions, one radiation-related cancer death would result. Radiation dose is thus an important issue in a lung cancer screening population because of the cumulative application of radiation dose to the patient's lung with repetitive screening CTs.

With one ultralow-dose CT acquisition of the lung phantom the effective dose was $0.074 \mathrm{mSv}$, compared to the $1.81 \mathrm{mSv}$ with standard acquisition. One standard acquisition thus exposed the lung phantom with a higher effective radiation dose than 13 ultralow-dose acquisitions (including the planning topograms). For the ultralow-dose acquisitions, the topogram even showed a higher effective dose than the actual CT acquisition.

There is an on-going debate on cost-effectiveness with an estimated cost of over US\$100,000 per quality-adjusted lifeyear gained, but could be lowered to US\$75,000 if linked to a smoking cessation programme [37]. Lung cancer screening results in incidental findings, some of which led to further investigations, resulted in moderate additional costs of $€ 8.95$ [US\$12.67] per patient at baseline and $€ 2.25$ [US\$3.19] at 5year follow-up [38]. Another point of discussion is the influence of indeterminate baseline screening results on the quality of life of the patients during lung cancer screening [39]. False- positive nodules led to biopsy in $1.2 \%$ of the patients who were not found to have lung cancer in both the NLST and the NELSON trial [36]. There are new biomarkers to stratify highrisk populations for lung cancer screening, which could result in a better performance of all the discussed points above [40]. But this is a subject of on-going investigations.

A major limitation of this study was the use of a lung phantom, which of course can never fully substitute for the 70-kg Asian man it represents. Moreover, real patients will have individual body constitutions that result in variations in the effective dose. Thus, CT acquisitions of the phantom are comparable to authentic CT acquisitions, but they will never replace $\mathrm{CT}$ acquisitions of real patients. Since patients in Europe and America normally weigh $80 \mathrm{~kg}$ and more, with many patients weighing over $100 \mathrm{~kg}$, these results may not be applicable to these populations. Thus, the results of this study have to be approved in a real setting.

Another limitation is the different lung convolution kernels used in this study: I70 for standard acquisition, I50 for the lung CAD software and I30 for the ultralow-dose acquisition. This was based on previous pilot studies that proved optimal detection rates with significantly better performance of the lung CAD software with the I50 convolution kernel and a softer I30 convolution kernel for the ultralow-dose acquisition compared to the standard I70 convolution kernel. The softer I30 convolution kernel for the ultralow-dose acquisition helps to compensate the decreased signal-to-noise ratio of the ultralow-dose acquisitions. Although the use of different convolution kernels might decrease comparability from the strict point of view of systematics, this allows comparison of the best possible performance of standard CT, ultralow-dose CT and the CAD software for lung nodules detection, as any radiologist would also try to achieve in a clinical setting with real patients.

Although the two formed read-out groups consisted of radiologists with comparable experience in thoracic radiology and used the same read-out settings, there are some differences between the two groups. The amount of time that the 
Table 6 The per-nodule diameter analysis: mean sensitivity of standard and ultralow-dose acquisitions with and without the assistance of maximum intensity projection (MIP) and computer-assisted detection (CAD)

\begin{tabular}{|c|c|c|c|c|c|c|c|c|}
\hline \multirow{2}{*}{$\frac{\text { Nodule size }}{5 \mathrm{~mm}}$} & \multicolumn{3}{|c|}{ Standard acquisitions } & \multicolumn{5}{|c|}{ Ultralow-dose acquisitions } \\
\hline & Sensitivity \pm SD & $\begin{array}{l}\text { Sensitivity with } \\
\mathrm{MIP} \pm \mathrm{SD}\end{array}$ & $\begin{array}{l}\text { Sensitivity with MIP } \\
\text { and } \mathrm{CAD} \pm \mathrm{SD}\end{array}$ & Sensitivity \pm SD & $\mathrm{p}_{1}$ & $\begin{array}{l}\text { Sensitivity with } \\
\mathrm{MIP} \pm \mathrm{SD}\end{array}$ & $\mathrm{p}_{2}$ & $\begin{array}{c}\text { Sensitivity with MIP } \\
\text { and } \mathrm{CAD} \pm \mathrm{SD}\end{array}$ \\
\hline \multirow[t]{2}{*}{ A } & \multirow[t]{2}{*}{$81.0 \% \pm 22.1 \%$} & $92.0 \% \pm 10.2 \%$ & $96.0 \% \pm 5.7 \%$ & \multirow[t]{2}{*}{$82.2 \% \pm 8.6 \%$} & \multirow[t]{2}{*}{0.864} & $89.1 \% \pm 6.3 \%$ & \multirow[t]{2}{*}{0.020} & $93.1 \% \pm 7.3 \%$ \\
\hline & & $\begin{array}{c}\text { Sensitivity with } \\
\mathrm{CAD} \pm \mathrm{SD}\end{array}$ & $\begin{array}{l}\text { Sensitivity with MIP } \\
\text { and } \mathrm{CAD} \pm \mathrm{SD}\end{array}$ & & & $\begin{array}{l}\text { Sensitivity with } \\
\text { CAD }\end{array}$ & & $\begin{array}{l}\text { Sensitivity with } \\
\text { MIP and CAD }\end{array}$ \\
\hline $\mathrm{B}$ & $98.9 \% \pm 1.0 \%$ & $100 \% \pm 0.0 \%$ & $100.0 \% \pm 0.0 \%$ & $85.6 \% \pm 8.6 \%$ & $<0.001$ & $93.7 \% \pm 4.5 \%$ & 0.12 & $93.7 \% \pm 4.5 \%$ \\
\hline Mean & $89.9 \% \pm 18 \%$ & & $98.0 \% \pm 4.5 \%$ & $83.9 \% \pm 8.8 \%$ & 0.008 & & & $93.4 \% \pm 6.1 \%$ \\
\hline $8 \mathrm{~mm}$ & Sensitivity \pm SD & $\begin{array}{l}\text { Sensitivity with } \\
\mathrm{MIP} \pm \mathrm{SD}\end{array}$ & $\begin{array}{l}\text { Sensitivity with MIP } \\
\text { and CAD }{ }^{S} \text { SD }\end{array}$ & Sensitivity \pm SD & $\mathrm{Pi}$ & $\begin{array}{l}\text { Sensitivity with } \\
\qquad \mathrm{MIP} \pm \mathrm{SD}\end{array}$ & $\mathrm{P} 2$ & $\begin{array}{l}\text { Sensitivity with } \\
\text { MIP and CAD }\end{array}$ \\
\hline \multirow[t]{2}{*}{ A } & \multirow[t]{2}{*}{$92.4 \% \pm 6.0 \%$} & $97.1 \% \pm 3.0 \%$ & $98.2 \% \pm 2.5 \%$ & \multirow[t]{2}{*}{$90.1 \% \pm 6.5 \%$} & \multirow[t]{2}{*}{0.424} & $95.3 \% \pm 4.4 \%$ & \multirow[t]{2}{*}{0.227} & $98.2 \% \pm 2.5 \%$ \\
\hline & & $\begin{array}{l}\text { Sensitivity with } \\
\mathrm{CAD} \pm \mathrm{SD}\end{array}$ & $\begin{array}{l}\text { Sensitivity with MIP } \\
\text { and } \mathrm{CAD} \pm \mathrm{SD}\end{array}$ & & & $\begin{array}{l}\text { Sensitivity with } \\
\mathrm{CAD} \pm \mathrm{SD}\end{array}$ & & $\begin{array}{l}\text { Sensitivity with MIP } \\
\text { and CAD }\end{array}$ \\
\hline $\mathrm{B}$ & $97.7 \% \pm 1.0 \%$ & $99.4 \% \pm 0.8 \%$ & $99.4 \% \pm 0.8 \%$ & $94.2 \% \pm 3.3 \%$ & 0.070 & $98.2 \% \pm 0.0 \%$ & 1.000 & $98.2 \% \pm 0.0 \%$ \\
\hline Mean & $95.0 \% \pm 5.0 \%$ & & $98.8 \% \pm 1.9 \%$ & $92.1 \% \pm 5.5 \%$ & 0.052 & & & $98.2 \% \pm 1.8 \%$ \\
\hline $10 \mathrm{~mm}$ & Sensitivity \pm SD & $\begin{array}{l}\text { Sensitivity with } \\
\mathrm{MIP} \pm \mathrm{SD}\end{array}$ & $\begin{array}{l}\text { Sensitivity with MIP } \\
\text { and } \mathrm{CAD} \pm \mathrm{SD}\end{array}$ & Sensitivity \pm SD & $\mathrm{Pi}$ & $\begin{array}{l}\text { Sensitivity with } \\
\quad \mathrm{MIP} \pm \mathrm{SD}\end{array}$ & $\mathrm{P} 2$ & $\begin{array}{c}\text { Sensitivity with MIP } \\
\text { and } C A D \pm S D\end{array}$ \\
\hline \multirow[t]{2}{*}{ A } & \multirow[t]{2}{*}{$96.3 \% \pm 5.2 \%$} & $97.5 \% \pm 3.5 \%$ & $97.5 \% \pm 3.5 \%$ & \multirow[t]{2}{*}{$98.8 \% \pm 1.7 \%$} & \multirow[t]{2}{*}{0.219} & $98.8 \% \pm 1.7 \%$ & \multirow[t]{2}{*}{0.219} & $98.8 \% \pm 1.7 \%$ \\
\hline & & $\begin{array}{l}\text { Sensitivity with } \\
\mathrm{CAD} \pm \mathrm{SD}\end{array}$ & $\begin{array}{l}\text { Sensitivity with MIP } \\
\text { and } \mathrm{CAD} \pm \mathrm{SD}\end{array}$ & & & $\begin{array}{l}\text { Sensitivity with } \\
\text { CAD }\end{array}$ & & $\begin{array}{l}\text { Sensitivity with MIP } \\
\text { and } C A D \pm S D\end{array}$ \\
\hline B & $99.4 \% \pm 1.1 \%$ & $100 \% \pm 0.0 \%$ & $100.0 \% \pm 0.0 \%$ & $99.4 \% \pm 0.9 \%$ & 1.000 & $99.4 \% \pm 0.9 \%$ & 1.00 & $99.4 \% \pm 0.9 \%$ \\
\hline Mean & $97.8 \% \pm 4.1 \%$ & & $98.8 \% \pm 2.8 \%$ & $99.1 \% \pm 1.4 \%$ & 0.289 & & & $99.1 \% \pm 1.4 \%$ \\
\hline $12 \mathrm{~mm}$ & Sensitivity \pm SD & $\begin{array}{l}\text { Sensitivity with } \\
\mathrm{MIP} \pm \mathrm{SD}\end{array}$ & $\begin{array}{l}\text { Sensitivity with MIP } \\
\text { and } \mathrm{CAD} \pm \mathrm{SD}\end{array}$ & Sensitivity \pm SD & p1 & $\begin{array}{l}\text { Sensitivity with } \\
\mathrm{MIP} \pm \mathrm{SD}\end{array}$ & $\mathrm{p} 2$ & $\begin{array}{l}\text { Sensitivity with MIP } \\
\text { and } C A D \pm S D\end{array}$ \\
\hline \multirow[t]{2}{*}{$\mathbf{A}$} & \multirow[t]{2}{*}{$98.4 \% \pm 0.0 \%$} & $99.5 \% \pm 0.7 \%$ & $100.0 \% \pm 0.0 \%$ & \multirow[t]{2}{*}{$97.4 \% \pm 2.0 \%$} & \multirow[t]{2}{*}{0.688} & $98.4 \% \pm 1.3 \%$ & \multirow[t]{2}{*}{1.000} & $98.9 \% \pm 1.5 \%$ \\
\hline & & $\begin{array}{c}\text { Sensitivity with } \\
\mathrm{CAD} \pm \mathrm{SD}\end{array}$ & $\begin{array}{l}\text { Sensitivity with MIP } \\
\text { and } \mathrm{CAD} \pm \mathrm{SD}\end{array}$ & & & $\begin{array}{l}\text { Sensitivity with } \\
\text { CAD }\end{array}$ & & $\begin{array}{l}\text { Sensitivity with MIP } \\
\text { and } C A D \pm S D\end{array}$ \\
\hline B & $99.5 \% \pm 0.9 \%$ & $99.5 \% \pm 0.7 \%$ & $99.5 \% \pm 0.7 \%$ & $98.9 \% \pm 1.5 \%$ & 1.000 & $99.5 \% \pm 0.7 \%$ & 1.000 & $99.5 \% \pm 0.7 \%$ \\
\hline Mean & $99.2 \% \pm 0.8 \%$ & & $99.7 \% \pm 0.6 \%$ & $98.1 \% \pm 1.9 \%$ & 0.508 & & & $99.2 \% \pm 1.2 \%$ \\
\hline
\end{tabular}

Both groups started with the 1-mm axial stacks, once looking at the standard acquisitions, once at the ultralow-dose acquisitions. In a second step, for both acquisitions, the readers additionally looked at MA reconstructions and used a CAD software. While group A first looked at the MIP reconstructions and then checked with the CAD software, group B first used the CAD software, finally checking with the MIP reconstructions

$S D$ standard deviation, $A$ group A, readout order 1. CT 2. MIP, $B$ group B, readout order 1. CT 2. CAD, $p_{1}$ standard acquisitions vs. ultralow dos acquisitions, $p_{2}$ standard dose acquisitions vs. ultralow-dose acquisitions with MIP and CAD

radiologists spent looking at the images was not calculated, and there might have been some differences depending on this factor. However, as long as human radiologists are not completely replaced by computer detection software, differences and some small fluctuation will occur. Nevertheless, the inter-reader variability in this study was very low (almost
Table 7 The per-nodule diameter analysis: mean sensitivity of ground-glass and solid nodules without additional maximum intensity projection/computerassisted detection (MIP/CAD)

\begin{tabular}{llllll}
\hline $\begin{array}{l}\text { Nodule } \\
\text { size }\end{array}$ & Ground-glass nodules & & & Solid nodules & \\
\cline { 2 - 3 } \cline { 5 - 6 } & $\begin{array}{l}\text { Ultralow dose } \\
\text { acquisition }\end{array}$ & $\begin{array}{l}\text { Standard } \\
\text { acquisition }\end{array}$ & & $\begin{array}{l}\text { Ultralow dose } \\
\text { acquisition }\end{array}$ & $\begin{array}{l}\text { Standard } \\
\text { acquisition }\end{array}$ \\
\hline $5 \mathrm{~mm}$ & $86.7 \% \pm 9.0 \%$ & $90.6 \% \pm 21.1 \%$ & & $81.0 \% \pm 9.1 \%$ & $89.3 \% \pm 15.2 \%$ \\
$8 \mathrm{~mm}$ & $96.7 \% \pm 3.8 \%$ & $97.8 \% \pm 3.0 \%$ & & $87.0 \% \pm 10.6 \%$ & $92.0 \% \pm 8.7 \%$ \\
$10 \mathrm{~mm}$ & $100.0 \% \pm 0.0 \%$ & $98.6 \% \pm 3.1 \%$ & & $98.3 \% \pm 2.5 \%$ & $97.2 \% \pm 4.9 \%$ \\
$12 \mathrm{~mm}$ & $100.0 \% \pm 0.0 \%$ & $100.0 \% \pm 0.0 \%$ & & $96.4 \% \pm 3.8 \%$ & $97.9 \% \pm 1.5 \%$ \\
\hline
\end{tabular}

The mean sensitivity per ground-glass and solid nodule size of both groups looking at the 1-mm axial stacks, once acquired with standard dose, once with ultralow-dose

$S D$ standard deviation 
perfect), and, as shown, the additional use of MIPs and CAD helped to lower these effects. This is another argument to use additional MIP-reconstructions or a lung CAD software.

\section{Conclusion}

Ultralow-dose CT, using the same dose as a conventional thoracic radiography on two planes, has a comparable sensitivity to standard CT for lung nodule detection, and is thus adequate for lung cancer screening. The small difference in detection rates between ultralow-dose $\mathrm{CT}$ and standard $\mathrm{CT}$ can be compensated for by using MIP reconstructions. The additional use of CAD software results in a slightly higher detection rate for the smallest solid micronodules of $5 \mathrm{~mm}$ used in this study. This might be helpful in staging for lung metastases in patients with known cancer, but is not necessarily beneficial in the setting of lung cancer screening, due to a high falsepositive rate of exactly those small solid micronodules.

Acknowledgments The scientific guarantor of this publication is Dr. Andreas Christe. The authors of this manuscript declare no relationships with any companies whose products or services may be related to the subject matter of the article. This study has received funding by the Bernese Cancer League, the Jubilee Foundation Swisslife and the Swiss Fight Against Cancer Foundation. The funders had no role in data collection, study design and analysis, preparation of the manuscript or decision to publish. One of the authors has significant statistical expertise. Institutional Review Board approval was not required because this was a phantom study. No study subjects or cohorts have been previously reported. Methodology: prospective, experimental, performed at one institution.

\section{References}

1. Jemal A, Bray F, Center MM et al (2011) Global cancer statistics. CA Cancer J Clin 61:69-90

2. Kaneko M, Eguchi K, Ohmatsu H et al (1996) Peripheral lung cancer: screening and detection with low-dose spiral CT versus radiography. Radiology 201:798-802

3. Henschke CI, Yankelevitz DF, Libby DM et al (2006) Survival of patients with stage I lung cancer detected on CT screening. N Engl J Med 355:1763-1771

4. The National Lung Screening Trial Team (2011) Reduced lungcancer mortality with low-dose computed tomographic screening. N Engl J Med 365:395-409

5. Field JK, van Klaveren R, Pedersen JH et al (2013) European randomized lung cancer screening trials: post NLST. J Surg Oncol 108: 280-286

6. van Iersel CA, de Koning HJ, Draisma G et al (2007) Risk-based selection from the general population in a screening trial: selection criteria, recruitment and power for the Dutch-Belgian randomised lung cancer multi-slice CT screening trial (NELSON). Int J Cancer 120:868-874

7. Wender R, Fontham ETH, Barrera E et al (2013) American cancer society lung cancer screening guidelines. CA Cancer J Clin 63: 106-117
8. Jaklitsch MT, Jacobson FL, Austin JHM et al (2012) The American association for thoracic surgery guidelines for lung cancer screening using low-dose computed tomography scans for lung cancer survivors and other high-risk groups. J Thorac Cardiovasc Surg 144:3338

9. Nair A, Hansell DM (2011) European and North American lung cancer screening experience and implications for pulmonary nodule management. Eur Radiol 21:2445-2454

10. Kauczor H-U, Bonomo L, Gaga M, et al. (2015) ESR/ERS white paper on lung cancer screening. Eur Respir J ERJ-00330-2015. doi: 10.1183/09031936.00033015

11. Mahadevia PJ, Fleisher LA, Frick KD et al (2003) Lung cancer screening with helical computed tomography in older adult smokers: a decision and cost-effectiveness analysis. JAMA J Am Med Assoc 289:313-322

12. Swensen SJ, Jett JR, Sloan JA et al (2002) Screening for lung cancer with low-dose spiral computed tomography. Am J Respir Crit Care Med 165:508-513

13. Brenner DJ (2004) Radiation risks potentially associated with lowdose CT screening of adult smokers for lung cancer. Radiology 231: 440-445

14. Baumueller S, Winklehner A, Karlo C et al (2012) Low-dose CT of the lung: potential value of iterative reconstructions. Eur Radiol 22: 2597-2606

15. Neroladaki A, Botsikas D, Boudabbous S et al (2013) Computed tomography of the chest with model-based iterative reconstruction using a radiation exposure similar to chest $\mathrm{X}$-ray examination: preliminary observations. Eur Radiol 23:360-366

16. Gordic S, Morsbach F, Schmidt B et al (2014) Ultralow-Dose chest computed tomography for pulmonary nodule detection: first performance evaluation of single energy scanning with spectral shaping. Invest Radiol 49:465-473

17. Valencia R, Denecke T, Lehmkuhl L et al (2006) Value of axial and coronal maximum intensity projection (MIP) images in the detection of pulmonary nodules by multislice spiral CT: comparison with axial 1-mm and 5-mm slices. Eur Radiol 16:325-332

18. Christe A, Leidolt L, Huber A et al (2013) Lung cancer screening with CT: evaluation of radiologists and different computer assisted detection software (CAD) as first and second readers for lung nodule detection at different dose levels. Eur J Radiol 82:e873-e878

19. Zhao Y, de Bock GH, Vliegenthart R et al (2012) Performance of computer-aided detection of pulmonary nodules in low-dose CT: comparison with double reading by nodule volume. Eur Radiol 22: 2076-2084

20. Ebner L, Bütikofer Y, Ott D et al (2015) Lung nodule detection by microdose $\mathrm{CT}$ versus chest radiography (standard and dual-energy subtracted). Am J Roentgenol. doi:10.2214/AJR.14.12921

21. ICRP (2007) The 2007 recommendations of the international commission on radiological protection. ICRP publication 103. Ann ICRP 37:1-332

22. Zar JH (2010) Biostatistical analysis. Prentice-Hall/Pearson, Upper Saddle River

23. Wilcoxon F (1946) Individual comparisons of grouped data by ranking methods. J Econ Entomol 39:269

24. Light RJ (1971) Measures of response agreement for qualitative data: some generalizations and alternatives. Psychol Bull 76:365377

25. Landis JR, Koch GG (1977) The measurement of observer agreement for categorical data. Biometrics 33:159-174

26. Schoonjans F, Zalata A, Depuydt CE, Comhaire FH (1995) MedCalc: a new computer program for medical statistics. Comput Methods Programs Biomed 48:257-262

27. Veronesi G, Maisonneuve P, Spaggiari L et al (2014) Diagnostic performance of low-dose computed tomography screening for lung cancer over five years. J Thorac Oncol 9:935-939 
28. Doo KW, Kang E-Y, Yong HS et al (2014) Comparison of chest radiography, chest digital tomosynthesis and low dose MDCT to detect small ground-glass opacity nodules: an anthropomorphic chest phantom study. Eur Radiol 24:3269-3276

29. Godoy MCB, Kim TJ, White CS et al (2013) Benefit of computer-aided detection analysis for the detection of subsolid and solid lung nodules on thin- and thick-section CT. Am J Roentgenol 200:74-83

30. Li Q, Li F, Doi K (2008) Computerized detection of lung nodules in thin-section CT images by use of selective enhancement filters and an automated rule-based classifier. Acad Radiol 15:165-175

31. Slattery MM, Foley C, Kenny D et al (2012) Long-term follow-up of non-calcified pulmonary nodules $(<10 \mathrm{~mm})$ identified during low-dose CT screening for lung cancer. Eur Radiol 22:1923-1928

32. Henschke CI, Yankelevitz DF, Naidich DP et al (2004) CT screening for lung cancer: suspiciousness of nodules according to size on baseline scans. Radiology 231:164-168

33. Travis WD, Brambilla E, Noguchi $M$ et al (2011) International association for the study of lung cancer/American thoracic society/european respiratory society: international multidisciplinary classification of lung adenocarcinoma. Proc Am Thorac Soc 8:381-385
34. MacMahon H, Austin JHM, Gamsu G et al (2005) Guidelines for management of small pulmonary nodules detected on CT Scans: a statement from the fleischner society. Radiology 237:395-400

35. Horeweg N, van Rosmalen J, Heuvelmans MA et al (2014) Lung cancer probability in patients with CT-detected pulmonary nodules: a prespecified analysis of data from the NELSON trial of low-dose CT screening. Lancet Oncol 15:1332-1341

36. Bach PB, Mirkin JN, Oliver TK et al (2012) Benefits and harms of ct screening for lung cancer: a systematic review. JAMA 307:2418-2429

37. McMahon PM, Kong CY, Bouzan C et al (2011) Cost-Effectiveness of CT screening for lung cancer in the U.S. J Thorac Oncol Off Publ Int Assoc Study Lung Cancer 6:1841-1848

38. Priola AM, Priola SM, Giaj-Levra M et al (2013) Clinical implications and added costs of incidental findings in an early detection study of lung cancer by using low-dose spiral computed tomography. Clin Lung Cancer 14:139-148

39. Bergh KAM, Essink-Bot M-L, Borsboom GJJM, et al. (2010) Long-term effects of lung cancer CT screening on health-related quality of life (NELSON). Eur Respir J erj01234-2010. doi: 10. 1183/09031936.00123410

40. Vansteenkiste J, Dooms C, Mascaux C, Nackaerts K (2012) Screening and early detection of lung cancer. Ann Oncol 23: x320-x327 